\title{
Occasional Drinker
}

National Cancer Institute

\section{Source}

National Cancer Institute. Occasional Drinker. NCI Thesaurus. Code C126382.

An individual who drinks from time to time, but generally less than once per week. 